\title{
Research on the Incentive Policy of Building Energy-saving in China
}

\author{
Lei Tian \\ JiLin Railway Technology College,China \\ 35831177@163.cm
}

Keywords: building, energy-saving, incentive policy

\begin{abstract}
Since the global energy crisis, more and more countries pay much attention to the energy saving field. Building energy consumption cannot be ignored in energy conservation. China's building energy consumption is much huge, and need effective measures to motivate energy conservation. In this paper, we discuss the problem of China's building energy-saving incentive system at present, and give some suggestions to the reform of the system.
\end{abstract}

\section{Introduction}

Energy saving comes from global energy crisis. Energy is an indispensable driving force for social and economic development, but it is limited. Growing energy crisis makes energy-saving become the consensus of the world. Also because of this, in the world, traditional economy based on a large number of raw materials and energy consumption is gradually losing the glory in the past. China has become the enormous energy-consuming country. Especially after the reform and opening up, China's construction industry is developing rapidly, in recent years, especially the reform of housing system promotes the development of housing industry and the national economy greatly with the result that the energy shortage has become a bottleneck for China's economic and social development, which has become an indisputable fact. On the other hand, compared with the advanced countries, there is a considerable gap between these countries and our country in the overall energy efficiency, the overall situation is not optimistic.

China is a big architecture energy consumption country, building materials and energy consumption during producing and constructing accounted for $44.2 \%$ of energy consumption of the whole society. The government attaches great importance to the building energy conservation, rules that the building energy efficiency achieve the planning objective that saving 1.6 million tons of standard coal during the Eleventh Five-Year plan period ${ }^{[1]}$. Existing accounting for residential construction area has a building area of about $85 \%$, it is the top priority of building energy conservation. But in view of the big differences between north and south, urban and rural areas in our country residential building energy consumption, we need a well-target policy and energy-saving technology. The lack of corresponding economic incentive policy is an important reason for the slow progress in energy conservation work, so there is an urgent need for the corresponding research.

\section{The necessity of building energy saving incentive}

With the problem of building energy consumption becoming more and more serious, building energy conservation has gotten great attention, and our country has promulgated a series of laws, regulations and norms. November 1, 1997, People's Republic of China Energy Conservation Law promulgated and implemented, the Standing Committee of the National People's Congress revised it in 2007, made a clear deployment of China's construction of energy-saving legislation framework blueprint. On August 1, 2008, the State Council promulgated the Civil Construction of Energy-saving Regulations, propose some requirements for the energy conservation of new construction, energy-saving transformation of existing buildings, building energy-efficient operation of the system and put forward specific requirements, clarify the legal responsibilities and obligations of the people's governments at various levels, construction units, design units, supervision units and construction units and related personnel in building energy-saving. On 
January 29, 2012, the government published the Existing Residential Building Energy Efficiency Retrofit Guide, gave some relevant suggestions in some aspects, such as energy saving design, energy-saving renovation project costs and energy-saving construction and renovation, construction quality control and acceptance. On May 9, 2012, the Ministry of Housing and Construction in the Twelfth Five-year Plan Building Energy-Saving Special Planning, clarify the main goal, guiding ideology, development path, major tasks and safeguard measures of the construction of energy-efficient during the Twelfth Five-Year program, based on the summary of the experiences and lessons on the past. In 2012, more than half of the country's local governments introduced relevant policies and local norms about the construction of energy-efficient, and put forward specific requirements on the work of building energy saving.

But practical experience shows that while our country rely on mandatory energy efficiency standards, noninterference the spontaneous behavior of stakeholders to promote the construction of energy-saving effect is not obvious. Current building energy efficiency standards and norms are more macro requirements, lack specific details of the practice, and it is difficult to give consideration to a variety of different types of buildings, so that its effectiveness is limited. Building energy-saving behavior is difficult to obtain respect and support only by means of simple administrative. Stakeholders is hard to obtain corresponding economic benefits and social benefits, so that is struggling to mobilize the enthusiasm and initiative of the people whose interest is related to the energy-saving building. But the enthusiasm and initiative of the stakeholders is the key factor to determine the degree of promotion of building energy efficiency.

The reason is that the building energy-saving industry whose market mechanism is semi failure, compulsory execute and hundred percent trust the executive orders is completely negate the market attribute of building energy-saving industry, the function of market mechanism in the construction of energy-efficient is hampered. The direct consequences of market mechanism negation is the denial of the market's positive effects it should have. Considering the characteristic of building energy-saving and the special situation of China, reasonable and effective building energy-saving economic incentive policies can mobilize the market mechanism of semi failure ${ }^{[2]}$, play a positive role in guiding the market, and mobilize the enthusiasm and initiative of various stakeholders. In order to promote the construction of economic incentive policies reasonably, optimize the allocation of resources, promote the orderly and healthy development of building energy saving, the government needs to make some relevant economic incentive policies and increase the market guidance.

\section{Problems in building energy efficiency incentive policy in China}

China's building energy saving work started in the last century eighty's, the central government and the Ministry of construction develop and implement a series of building energy-saving incentive policies, mainly summarized as the following six types of building energy efficiency incentive policy, including: 1) residential energy-saving fixed assets investment direction adjustment tax; 2) energy-saving building products have the preferential income tax; 3) energy-saving building value-added tax preferential policies; 4) energy-saving building preferential loans; 5) energy-saving building funds or special funds; 6) energy-saving building heat price policy $^{[3]}$. Although these policies have promoted the development of building energy conservation, in general, the mandatory intervention is more than economic incentives, and lead to the following issues.

(1)Building energy-saving economic incentive policy in the form of a single. In most fields of building energy efficiency, economic incentive policies in our country mainly are financial subsidies, tax incentives and subsidized loans are used less. Discount-interest loan only carried out in the demonstration pilot project of the construction supervision system, the form of economic incentive measure is relatively single. Our country did not establish a special energy-saving fund, also do not levy the corresponding energy tax, funds mainly come from government funds, the channel is single, and this motivation pattern is a great consumption of government budget, it cannot be a good and suitable energy-saving building strategy of for a long time. In addition, most 
of the economic incentive policies of building energy saving in China are established in recent years, most of them are just stay in the macro level of laws and regulations, and they are not strong at maneuverability.

(2)Building energy-saving economic incentive policy is lack of level ${ }^{[4]}$. Building energy conservation mainly involves the central and local governments, real estate developers, design and construction units, home owners, property management companies, energy service companies, materials and equipment supplier and research institutions. The subjects of different levels is different, and the benefits they get directly or indirectly from energy-saving buildings are different as well. Effective motivation should design the incentive measures according to the benefits of different subjects. However, current motivation policies mostly start from the central, while the local economic incentive policies are rare. Due to the insufficient multi-level incentives in local, it cannot produce a small change from the top and enlarged gradually to the bottom, just like "Butterfly Effect", so that the construction of energy-saving transformation development is much slow.

(3)Building energy-saving incentive policies' positive motivation and negative motivation are not strong enough. In the field of building energy-saving incentive policy includes both positive incentives, such as financial subsidies, tax relief, price concessions, and discount-interest loans. There are also some negative incentives, such as mandatory intervention, sewage fee collection, the energy tax and so on. Due to the funding gap in our country is relatively large, positive incentive is insufficient. Take the building energy-saving reform as a example. Our country gives out annual financial subsidies for about 40 billion yuan for all the existing buildings' energy-saving transformation, but when it is apportioned to the large-scale construction, the financial subsidies they can get is about only 2.6 billion. The incentive power is far from enough to the huge existing building area, it is unable to mobilize the owners' enthusiasm. What is more, China's building energy-saving limitation policy is also relatively scarce

(4)Supporting measures of building energy-saving incentive policy is incomplete. The implementation of economic incentive policy depends on the perfect supporting measures of building energy-saving service market, mechanism of energy price, energy audit and evaluation system. However, at present, these supporting measures are still not perfect in China. The excess electricity pricing mechanism has not yet formed in the construction area, electricity price difference at peak valley is not obvious, and the energy excess fare system is in slow progress. In developed countries, the implementation of energy-saving economy incentive policies depends on the development of energy conservation service market development. But the building energy-saving service market has not yet been formed in our country, which greatly hindered the actualization of economic incentive policy.

\section{Suggestion and prospect of building energy-saving incentive policy in China}

International experience for reference.In the western developed countries, idea on the construction energy-saving has been constantly updated in the past 40 years. They initially advocated building energy-saving, then stressed to reduce energy loss while constructing. In the 1990s, the direction was to improve the energy utilization rate of the construction. Since the new century, the theme of building energy-saving is the sustainable use of buildings energy. Today in Europe, there has been the extremely stringent residential zero energy consumption standards, zero $\mathrm{CO}_{2}$ emission standards and energy self-sufficiency standard, these standards already get promotion and application partly. The building energy-saving of the western developed countries initially mainly rely on administrative orders, policies and standards of the government. At the beginning, the government's executive orders and policies, the implementation of standards in practice has played a great role in a long period of time to a large extent. Along with the deepening of the building energy conservation, building energy conservation standards are getting higher and higher, building energy-saving connotation is more and more abundant, building energy-saving control becoming more and more complex, and all of these reveal the disadvantages of mandatory means, such as low efficiency and high cost. Through exploration to different degree and by different ways, 
the countries choose the way to combine administrative compulsory means and economic incentives, and the practice shows its rationality.

In Japan, for the sake of reducing energy consumption and protecting the environment as far as possible, while ensure the growth of the national economy growth not to be affected, Japan mainly focus on two aspects. On the one hand, the Japanese government increase in appropriations for the support of building energy-saving and application development. The funds that Japanese government invested in energy research and development is about $1 \%$ of its GDP, in which about $8 \%$ is invested in the field of energy saving ${ }^{[5]}$. On the other hand, the investment in the field such as building energy conservation can enjoy the interest rates, discount loans, loan guarantees, tax incentives, special depreciation incentive policies from special one to five level to promote the building energy saving. In the United States, the United States federal government and state governments formulate a series of energy-saving promotion policy, including economic incentives, involving tax relief, tax incentives, energy-saving housing model demo, energy-saving materials recommendation, energy-saving funds investment, and so on, to promote the energy-saving construction and technology ${ }^{[6]}$.

Some suggestions.First of all, Strengthen the functions of government management ability, highlighting the dominant position of the government in building energy saving. The experience of developed countries shows that the construction of energy-saving work should be promoted by government firstly. Through the market expansion, form the building energy saving service system, which providing a set of services, including project investment, design, construction, monitoring, and management. Countries who have good effect in energy establish a special energy-saving management institutions, and the government's function in the field of energy conservation has been strengthened. At present, the leading role of governments at all levels in the energy-saving incentive mechanism has yet to be strengthened.

Secondly, introducing the market-based diversity incentive measures gradually. There are many places to be improved in building energy-saving incentive. These problems are mainly reflected in two aspects, one is China's energy price formation mechanism has not yet been completed, enterprises under the environment of low energy prices are lack of motivation to saving energy, reducing consumption, improve and apply energy-saving technologies. The other is our country's energy conservation intensity is weak at present, the financial investment is obviously insufficient, the tax policy is also not perfect.

Thirdly, relying on the government, cultivate the building energy-saving service system to do the energy conversation work. Introducing the market-oriented energy-saving reform step by step, and gradually establish and improve the energy-saving service market in china. On the one hand, we must continue to improve the energy service companies' abilities in carrying out large construction energy diagnosis analysis, energy-saving technology consultation, energy-saving financing ability, and following the international level. On the other hand, it is recommended as soon as possible to deliver fiscal and tax preferential policies and energy conservation financing policies that encourage the implementation of building energy-saving project, and actively support people to explore the building energy-saving service mode which conforms to the China's nation conditions.

\section{Summary}

The building energy-saving incentive system in China is far from perfect, although many related policies has been introduced. We firstly stressed out the importance of the building energy-saving incentive measures, and analysis the disadvantages in current motivation system. Through the study of western developed countries' effective and reasonable measures, combining our country's special nation conditions, we give some recommendations to the reform of China's building energy-saving incentive system. 


\section{References}

[1] Price L, Levine $\mathrm{M}$ D, Zhou $\mathrm{N}$, et al. Assessment of China's energy-saving and emission-reduction accomplishments and opportunities during the 11th Five Year Plan. Energy Policy, 2011, 39(4): 2165-2178.

[2] Hou J, Liu Y, Wu Y, et al. Comparative study of commercial building energy-efficiency retrofit policies in four pilot cities in China. Energy Policy, 2016, 88: 204-215.

[3] Li J, Shui B. A comprehensive analysis of building energy efficiency policies in China: status quo and development perspective. Journal of Cleaner Production, 2015, 90: 326-344.

[4] Liu Q, Feng W. Research on the Efficiency and Economic Impact of Energy-Saving Transformation of Residential Buildings in Different Climatic Regions of China. Advances in Materials Science and Engineering, 2015, 2015.

[5] Huang B, Mauerhofer V, Geng Y. Analysis of existing building energy saving policies in Japan and China. Journal of Cleaner Production, 2016, 112: 1510-1518.

[6] Liu R, Xu Y. Comparison of International Incentive Policy of Green Building[C]//Proceedings of the 5th International Asia Conference on Industrial Engineering and Management Innovation (IEMI2014). Atlantis Press, 2015: 319-323. 